\title{
Laju Ekploitasi Lobster Batu Panulirus penicillatus, Olivier, 1791 (Malacostraca : Palinuridae) di Perairan Laut Yogyakarta
}

\author{
Irwani*, Widy Febriansyah, Agus Sabdono dan Diah Permata Wijayanti \\ Departemen Kelautan, Fakultas Perikanan dan Ilmu Kelautan, Universitas Diponegoro \\ JI. Prof. Soedarto, SH. Kampus UNDIP Tembalang, Semarang 50275 \\ Email : irwani.semarang@gmail.com
}

\begin{abstract}
The Rate of Exploitation Panulirus penicillatus, Olivier, 1791 (Malacostraca : Palinuridae) in Yogyakarta Waters
\end{abstract}

Indonesia is an area that has various types of beaches with different topography and is a region producing one of the lobsters that have a very high economic value. Yogyakarta had three coastal districts that have lobster produce that is Kulonprogo Regency, Bantul Regency and Gunung Kidul Regency. This research aims to know exploitation rate, the growth model of Von Bertalanffy, mortality of pronghorn spiny lobster (Panulirus Penicillatus) in Yogyakarta Special Region. Data were collected at three beaches namely Depok, Congot and Baron coastal waters. Data was analyse used FISAT II software. The distribution of carapace lengths of stone lobster caught during the research ranged from 40,2-102 $\mathrm{mm}$ and the results indicated that the dominant lobster was caught with the highest number of catches below the midterm size of $76,3 \mathrm{~mm}$. Total mortality (Z) 4,251, natural mortality (M) 0,708, taking mortality (F) 3,543, and exploitation rate (E) 0,833 so that the mortality due to taking value of spiny lobster is much higher than natural mortality.

Keywords : Exploitation rate, Von Bertalanffy; Mortality

\begin{abstract}
Abstrak
Indonesia adalah daerah yang mempunyai berbagai jenis pantai dengan topografi yang berbeda-beda serta merupakan daerah penghasil salah satu lobster yang memiliki nilai ekonomis sangat tinggi. Yogyakarta memiliki tiga Kabupaten wilayah pantai yang memiliki hasil lobster yaitu Kabupaten Kulon Progo, Kabupaten Bantul dan Kabupaten Gunung Kidul. Penelitian ini bertujuan untuk mengetahui tingkat pemanfaatannya, mortalitas, model pertumbuhan von bertalanffy lobster batu (Panulirus penicillatus) di Daerah Istimewa Yogyakarta. Data diperoleh di tiga pesisir yauitu, Pesisr Depok, Congot dan Baron. Pengolahan data dilakukan dengan menggunakan FISAT II. Distribusi ukuran panjang karapas lobster batu yang tertangkap selama penelitian berkisar antara 40,2-102, mm dan hasil menunjukkan bahwa lobster dominan tertangkap yang jumlah hasil tangkapnya paling banyak dibawah ukuran nilai tengah $76,3 \mathrm{~mm}$. Panjang total lobster memiliki ukuran terpendek $22,1 \mathrm{~cm}$ dan terpanjang $83,4 \mathrm{~cm}$. Hasil yang didapatkan laju mortalitas total (Z) 4,251, nilai mortalitas alami (M) 0,708, mortalitas penangkapan (F) 3,543 dan laju eksploitasinya (E) 0,833 sehingga diketahui nilai mortalitas penangkapan dari lobster batu jauh lebih tinggi dibandingkan mortalitas akibat alami.
\end{abstract}

Kata Kunci Laju ekploitasi; Von Bertalanffy; Mortalitas

\section{PENDAHULUAN}

Indonesia adalah negara yang beriklim tropis dimana perairannya mempunyai kesuburan yang tinggi. Termasuk di dalamnnya ekosistem terumbu karang yang merupakan habitat organisme ekonomis penting seperti lobster (Panulirus spp). Daerah Istimewa Yogyakarta dengan ibukota Kota Yogyakarta adalah daerah 
yang mempunyai berbagai jenis pantai dengan topografi yang berbeda - beda serta merupakan daerah penghasil salah satu hasil laut yang memiliki nilai ekonomis sangat tinggi yaitu lobster. Terdapat tiga Kabupaten wilayah pantai yang memiliki hasil lobster yaitu Kabupaten Kulon Progo, Kabupaten Bantul dan Kabupaten Gunung Kidul.

Lobster hidup dengan bagian tubuh lengkap yang dihargai lebih tinggi di pasaran. Perikanan lobster di setiap wilayah perairan pantai di Indonesia dengan habitat yang sesuai merupakan salah satu kegiatan industri perikanan tangkap yang berbasis masyarakat yang memiliki keunggulan komperatif karena potensi sumber daya lokal yang cukup besar, permintaan pasar dan harga yang tinggi (Kusuma et al, 2012) .

Habitat lobster merupakan hewan laut yang hidup dikawasan terumbu karang perairan - perairan dangkal hingga $100 \mathrm{~m}$ permukaan laut. Kehidupan lobster juga penyebarannya sangat luas. Lobster merupakan habitat yang sangat menyukai wilayah kehidupannya di tempat-tempat yang sifatnya terbuka dan terlebih arus yang kuat (Kadafi et al., 2006).

Lobster memiliki sifat yang nokturnal (aktif malam hari) dan suka bergerombol. Musim penangkapan lobster terjadi pada musim hujan, pada hari bulan gelap, terutama setelah bulan purnama. Jangka waktu hidup lobster antara 8 sampai 10 tahun. Lobster pada siang hari bersembunyi di antara karang, gua - gua karang dan malam hari keluar dari tempat persembunyiannya, mengembara mencari makan hingga ditempat - tempat relatif yang dekat dengan daratan pantai terutama pada waktu air pasang (Ernawati et al, 2014).

Lobster Batu (Panilurus penicillatus) merupakan salah satu jenis habitat lobster laut yang hidup berada didasar perairan. Lobster Batu (Panilurus penicillatus) merupakan hewan yang hidup di substrat berbatu, berpasir atau berlumpur dan biasanya bersembunyi di celah-celah atau di bawah karang-karang batu dan atau di daerah terumbu karang baik di daerah tropis maupun sub-tropis. Sebagai hewan yang bersifat omnivora lobster akan memakan mangsa hidup seperti ikan, moluska, krustasea kecil, cacing, dan beberapa tumbuhan (Zaenudin dan Denada, 2017).

Spesies Lobster Batu (Panilurus penicillatus) memiliki distribusi yang sangat luas, membentang dari Samudera Hindia Barat hingga Pasifik Timur. Lobster adalah invertebrata dengan pelindung luar yang keras. Seperti kebanyakan arthropoda, lobster harus melewati beberapa fase pergantian kulit untuk tumbuh (Fauzi et al, 2013). Penelitian ini bertujuan untuk mengetahui tingkat pemanfaatannya, mortalitas, model pertumbuhan von bertalanffy lobster batu (Panulirus penicillatus) di Daerah Istimewa

Yogyakarta.

\section{MATERI DAN METODE}

Lobster batu (Panilurus penicillatus) yang digunakan dalam penelitian ini adalah lobster hasil tangkapan nelayan di perairan Daerah Istimewa Yogyakarta dengan menggunakan alat tangkap jaring insang tetap di tiga pendaratan ikan yaitu Pantai Congot, Pantai Depok dan Pantai Baron selama 4 (empat bulan) pada bulan Desember 2017, Januari 2018, Pebruari 2018, Maret 2018. Dimana pada bulan-bulan ini adalah musim Lobster di perairan tersebut, di luar bulan tersebut, Lobster tertangkap dalam jumlah yang sangat sedikit dan bahkan tidak tertangkap. Pengamatan pengukuran panjang lobster di lakukan dengan mengukur panjang karapas dan berat.

Hasil pengukuran panjang karapas untuk kemudian di tabulasi menggunakan Microsoft excel dan di bagi menjadi kelaskelas panjang. Model pertumbuhan berbasis panjang lobster dikemukaan oleh Von Bertalanffy, kemudian dikenal dengan Model Von Bertalanffy dengan rumus (Sparre dan Venema, 1999).

Nilai $L \infty$ dan $K$ didapatkan dari hasil perhitungan dengan ELEFAN 1 yang terdapat dalam program FISAT II, sedangkan untuk mendapatkan nilai to dapat menggunakan rumus empiris Pauly (Pauly, 1984).

Kemudian, seluruh nilai yang telah didapatkan untuK $L \infty, K$, dan to dimasukkan kedalam rumus Von Bertalanffy sehingga didapatkan persamaannya dan grafik 
pertumbuhannya. Hal ini dilakukan untuk mengetahui pertumbuhan panjang lobster batu selama umur tertentu hingga mencapai panjang asimtotiknya.

Laju mortalitas total (Z) dari rata-rata ukuran pada penangkapan dapat diketahui apabila sejumlah besar data frekuensi panjang didapatkan dari stok dengan alat tangkap yang ada, sehingga nilai $Z$ dapat diestimasikan dari panjang rata-rata lobster $(\bar{L})$ dalam setiap tangkapan dari populasi (Beverton dan Holt, 1956 dalam Pauly, 1984). Demikian juga perhitungan nilai mortalitas alami (M), martalitas Penangkapan (F) dan Laju exploitasi ( E ).

\section{HASIL DAN PEMBAHASAN}

\section{Pertumbuhan Von Bertalanffy}

Jumlah keseluruhan sampel lobster jenis Panulirus penicillatus yang diteliti adalah sebanyak 1140 ekor.

Parameter Pertumbuhan lobster meliputi nilai $K$ yaitu koefisien pertumbuhan lobster yang berhubungan dengan panjang asimtotik $(L \infty)$, yaitu panjang yang dapat dicapai oleh lobster selama pertumbuhan hingga umurnya tua, sedangkan to adalah umur imajiner lobster pada saat mempunyai panjang $0 \mathrm{~cm}$.

Grafik kurva pertumbuhan lobster mengalami peningkatan, menurut perhitungan Von Bertalanffy mendapatkan hasil nilai $L_{0 o}=103,31, K=0,560$ dan $t_{0}=$ 1,01403 .

\section{Kurva Pertumbuhan}

Parameter pertumbuhan diolah menggunakan software FISAT II sehingga didapatkan nilai $K$ dan $L^{\infty}$. Berdasarkan parameter pertumbuhan lobster di atas, maka bentuk persamaan dari Von Bertalanffy adalah $L t=103,31 \quad(1-\exp (-0,560(t+1,01403)))$ dengan bentuk kurva pertumbuhannya (Gambar 4)

Kurva pertumbuhan lobster yang berada di Daerah Istimewa Yogyakarta mendapatkan $\log k=0.560, L_{\infty}=103,31 \mathrm{~mm}$ dan nilai to $=-1,01403$. Nilai ini mendekati hasil penelitian Zaenuddin dan Denada (2017), yang mendapatkan Lo Panulirus penicillatus di perairan Wonogiri sebesar $134 \mathrm{~mm}$. Hasil perhitungan kelompok umur pada bulan Desember sampai dengan Maret 2018.

Tabel 3. Nilai Parameter Pertumbuhan Lobster Batu (Panulirus penicillatus)

\begin{tabular}{cc}
\hline Parameter & Nilai \\
\hline$K$ & 0,560 \\
$L_{\infty}$ & 103,31 \\
$t_{0}$ & $-1,01403$ \\
\hline
\end{tabular}

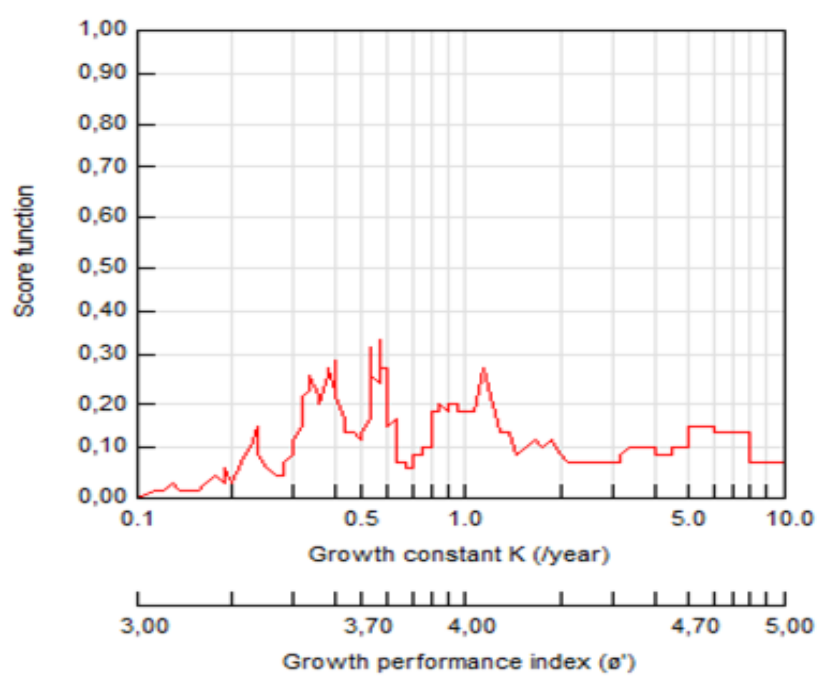

Gambar 3. Hasil Output K-Scan dari Software FISAT II. 


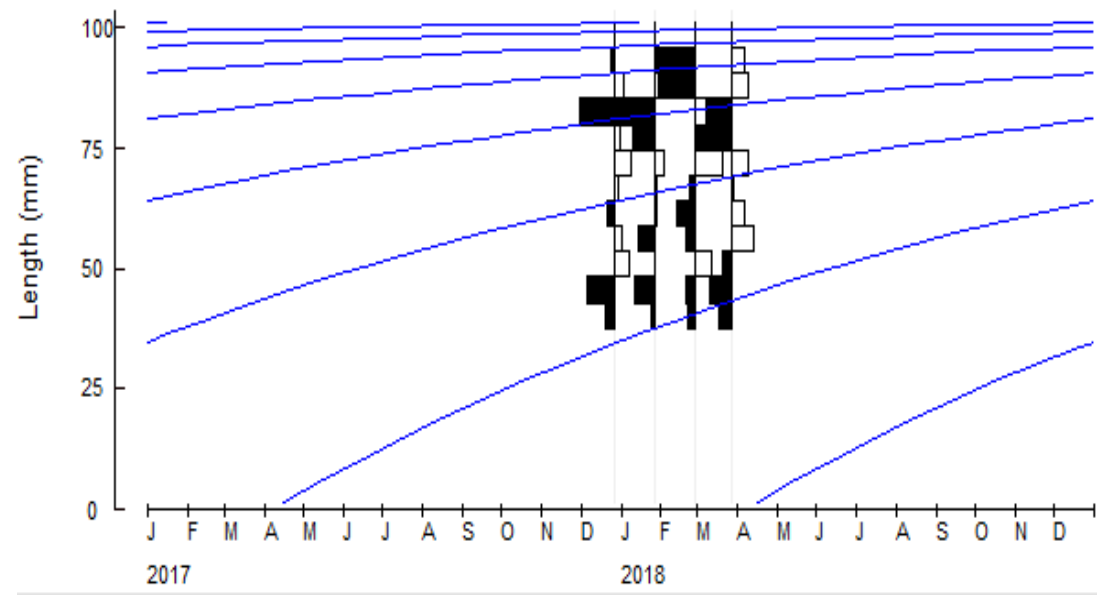

Gambar 4. Hasil Output Plot VBGF dari Software FISAT II.

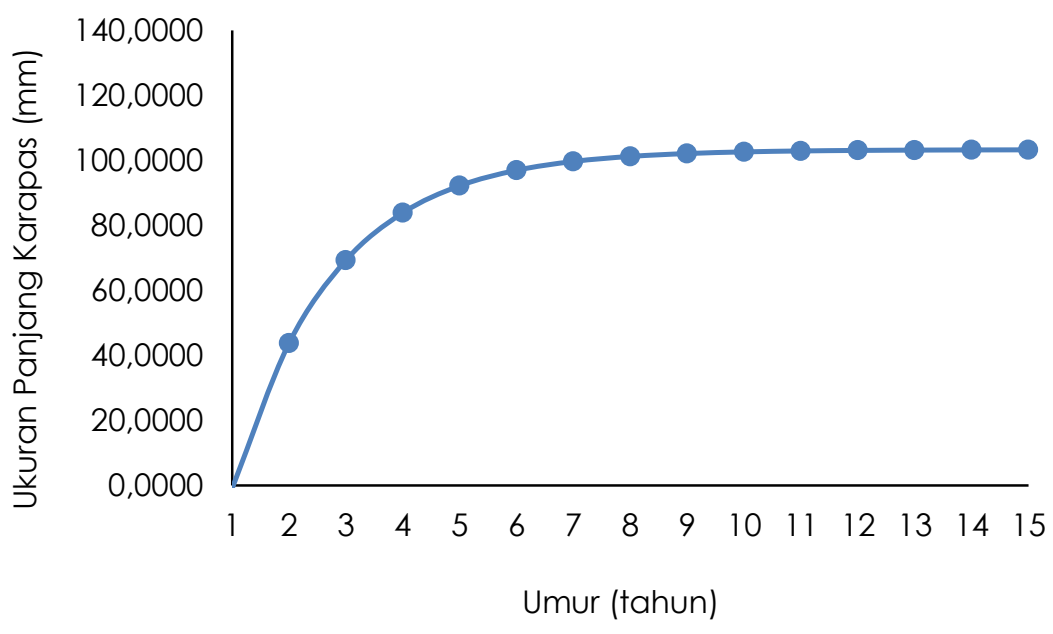

Gambar 4. Kurva Pertumbuhan Lobster

Model pertumbuhan lobster digambarkan mulai umur 1 tahun sampai 15 tahun. Masing-masing kelompok umur memiliki rentang 1 tahun. Pada tahun ke 15 panjang karapas lobster sudah mencapai nilai asymptote sebesar 103,31. Dapat disimpulkan bahwa lobster dapat mencapai ukuran ekonomis pada umur lebih dari 4 tahunan. Ukuran yang kurang ekonomis sangat merugikan nelayan karena nilai jual lobster yang rendah dan dari sisi pengelolaan banyaknya ukuran lobster yang masih kecil apabila tertangkap dapat berpotensi terhadap growth overfishing.

\section{Mortalitas}

Berdasarkan data penelitian diketahui nilai panjang rata-rata lobster batu (Panulirus

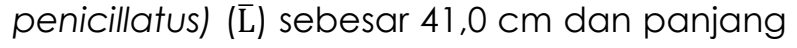

lobster batu ( $P$. penicillatus) terkecil (L') adalah $22,1 \mathrm{~cm}$, sehingga dapat ditentukan laju mortalitas total (Z). Menurut perhitungan Beverton dan Holt (1956) yang didapatkan laju mortalitas total (Z) 4,251, dan dari perhitungan Pauly (1984) didapatkan nilai mortalitas alami (M) 0,708, mortalitas penangkapan (F) 3,543 , hingga laju eksploitasinya (E) 0,833 . Hasil penelitian di perairan sekitarnya yaitu di perairan Cilacap Jawa Tengah mendapatkan mortalitas Lobster Batu Hijau ( $P$. hommarus) total (Z) sebesar 1,6 pertahun dan mortalitas alaminya (M) sebesar 0,69 pertahun. Mortalitas penangkapan (F) sebesar 0,91 per tahun. Dan tingkat eksploitasi (E) didapatkan sebesar 0,57 per tahun Bakhtiar et al. (2013). Tingkat explitasi yang jauh lebih tinggi dari penelitian sebelumnya mengindikasikan 
beberapa hal, kemungkinan pertama adalah terjadi peningkatan penangkapan lobster Batu (Panulirus Penicillatus) di pantai Selatan Jawa antara periode tahun 2012 sampai tahun 2018, ataupun mebgindikasikan bahwa penangkapan lobster di Yogyakarta lebih tinggi dari perairan Cilacap.

Nilai mortalitas penangkapan dari lobster batu jauh lebih tinggi dibandingkan mortalitas alami. Mortalitas alami disebabkan adanya pemangsaan, penyakit, stres pemijahan, kelaparan, dan usia tua. Mortalitas alami ini juga berkaitan dengan ekosistem, spesies yang sama di perairan berbeda mungkin memiliki laju mortalitas yang berbeda tergantung dari kepadatan pemangsa dan pesaing yang kelimpahannya dipengaruhi oleh aktifitas penangkapan di perairan tersebut. Rumus empiris Pauly (1984) yang digunakan pada penelitian ini, menunjukkan bahwa lobster mempunyai mortalitas alami yang berubah apabila suhu perairan juga berubah.

Menurut Setyono (2006) kenaikan suhu dari $25-28^{\circ} \mathrm{C}$ perairan dapat menurunkan kelarutan oksigen dalam air yang dapat berpengaruh langsung terhadap aktivitas lobster dan dapat menaikkan daya racun suatu polutan terhadap organisme perairan. Perubahan suhu lingkungan juga akan mempengaruhi metabolisme yang dapat mengakibatkan sebagian besar energi yang tersimpan dalam tubuh lobster digunakan untuk penyesuian diri terhadap lingkungan.

Menurut Pauly (1984), dengan mengasumsikan laju eksploitasi optimum (Eopt) $=0,5$, laju eksploitasi juga dapat menjelaskan status suatu stok lobster di perairan. Apabila nilai laju eksploitasi dari lobster melebihi angka optimumnya yaitu 0,5, maka dapat dikatakan stok lobster di perairan tersebut telah terjadi overfishing Selain itu, pendugaan stok lobster di perairan diekploitasi secara optimal adalah ketika nilai mortalitas penangkapan (F) sama dengan mortalitas alaminya (M). Laju eksploitasi Lobster Batu ( $P$. penicillatus) di Perairan DIY masuk dalam kategori membahayakan karena terjadi overfishing dengan nilai eksploitasi sebesar 0,833 per tahunnya, artinya hanya $83,3 \%$ kematian Lobster Batu (P. penicillatus) di Perairan DIY disebabkan oleh tangkapan manusia.
Tabel 5. Laju Mortalitas dan Laju Eksploitasi dari Lobster Batu (P. penicillatus)

\begin{tabular}{lc}
\hline \multicolumn{1}{c}{ Mortalitas } & Nilai (per tahun) \\
\hline Total (Z) & 4,251 \\
Alami (M) & 0,708 \\
Penangkapan (F) & 3,542 \\
Laju Eksploitasi (E) & 0,833 \\
\hline
\end{tabular}

\section{KESIMPULAN}

Berdasarkan hasil penelitian, diketahui bahwa laju pertumbuhan lobster batu $P$. penicillatus di Perairan Daerah Istimewa Yogyakarta, memiliki koefisien pertumbuhan (K) sebesar 0,560 per tahun dengan panjang asimtotik $\left(L_{\infty}^{\infty}\right)$ 103,31, dan umur imajiner lobster pada saat panjangnya $0 \mathrm{~cm}$ (to) adalah -1.01403. Laju mortalitas alami (M) lobster batu (Panulirus penicillatus) sebesar 0,708 per tahun dan mortalitas total (Z) 4,251 per tahun sedangkan mortalitas penangkapannya (F) hanya senilai 3,542 dengan laju eksploitasi 0,833 artinya $83,3 \%$ kematian lobster batu (Panulirus penicillatus) yang hidup di Perairan Daerah Istimewa Yogyakarta diakibatkan oleh aktivitas penangkapan.

\section{DAFTAR PUSTAKA}

Bakhtiar, N.M., Soichin, A., \& Saputra, S.W. 2013. Pertumbuhan dan laju Mortalitas Lobster Batu Hijau (Panulirus homarus) di perairan Cilacap Jawa Tengah. Jawa Tengah. Manag. Aqua. Res. J., 2(4):1-10

Ernawati, T., Kembaren, D.D., Suprapto., \& Sumiono, B. 2014. Parameter Populasi Lobster Bambu (Pannulirus versicolor) di Perairan Utara Kabupaten Sikka dan Sekitarnya. Bawal, 6(3):169-175.

Fauzi, M., Andhika, P.P., Ignatius, T.H., Fayakun S., \& Andria, A.U. 2013. Hubungan Panjang - Berat dan Faktor Kondisi Lobster Batu (Panulirus penicillatus) Di Perairan Selatan Gunung Kidul dan Pacitan. Jawa. Bawal, 5(2):97-102.

Kadafi, M., Widaningroem, R., \& Soepamo. 2006. Aspek Biologi dan Potensi Lestari Sumberdaya Lobster (Panulirus sp.) di Perairan Pantai Kecamatan Ayah Kabupaten Kebumen. J. Perikanan. 1:108-117.

Kusuma, R.D., Asriyanto, \& Sardiyatmo. 2012. Pengaruh Kedalaman dan Umpan 
Berbeda Terhadap Hasil Tangkapan Lobster (Panulius sp) dengan Jaring Lobster (Bottom Gill Net Monoflament) Di Perairan Argopeni Kabupaten Kebumen. J. Fish. Res. Utilization Manag. Technol. $1(1): 11-21$.

Pauly, D. 1984. Some Simple Methods for The Assesment of Tropical Fish Stocks. Food and Agriculture Organization of The United Nations. Roma.
Setyono, D.E.D. 2006. Budidaya Pembesaran Udang Karang (Panulirus spp). Oseana, $31(4): 39-48$.

Sparre, P., \& Venema, S.C. 1999. Introduksi Pengkajian Stok Ikan Tropis. Edisi Bahasa Indonesia. Puslitbangkan. Jakarta.

Zaenudin, M. \& Denada, A.D.P., 2017. Sebaran Ukuran Lobster Batu (Panulirus penicillatus) Di Wonogiri. Jawa Tengah. Saintek Perikanan, 12(2):109-115 